\title{
Poly(butylene 2,5-furandicarboxylate-e-caprolactone): A new bio-based elastomer with high strength and biodegradability
}

\author{
M. Y. Zheng, X. L. Zang, G. X. Wang, P. L. Wang, B. Lu, J. H. Ji \\ National Engineering Research Center of Engineering Plastics, Technical Institute of Physics and Chemistry, Chinese \\ Academy of Sciences
}

Received 30 December 2016; accepted in revised form 28 February 2017

\begin{abstract}
A new bio-based elastomer, poly(butylene 2,5-furandicarboxylate- $\varepsilon$-caprolactone) (PBFCL), has been synthesized from 2,5-furandicarboxylic acid, 1,4-butanediol, and $\varepsilon$-caprolactone successfully for the first time. The obtained copolyester was characterized in terms of chemical structure, thermal and mechanical properties, and enzymatic degradability. In PBFCL elastomer, butylene-2,5-furandiacrboxylate units (hard segments) crystallize to serve as physical crosslinks while $\varepsilon$-caprolactone polyester diol (soft segments) provide flexibility. PBFCL is a multi-blocked copolyester with randomly distributed rigid and soft segments. It possesses original feature of high strength and biodegradability stemming from the uses of aromatic and aliphatic monomers respectively. An important aspect of this new furanic-aliphatic polyester is its tailor-made properties simply achieved by changing the content of hard or soft segments. Typically, PBFCL-40 of optimal composition has Young's modulus as low as $15.4 \mathrm{MPa}$, tensile strength as high $24.8 \mathrm{MPa}$, and elongation as long as $885 \%$.
\end{abstract}

Keywords: biodegradable polymers, elastomers, mechanical properties, thermal properties, bio-based polymers

\section{Introduction}

Recently, biomass chemicals are being intensively exploited to address the depletion of non-renewable resources and over emission of greenhouse gases in polymer industry. Among plenty of bio-based chemicals, 2,5-furandicarboxylic acid (FDCA) stands out as the only aromatic diacid building block, which guarantees adequate thermomechanical properties of the ensuing polymers [1-3]. Normally, FDCA is produced by oxidation or biotransformation of hydroxymethyl furfural (HMF) [4], and HMF can be obtained from dehydration of plant-based sugars [5, 6]. FDCA has been investigated intensively both in academia and industry because it is a perfect bio-based substitute to the petroleum-based terephthalate acid (TPA), which is a versatile monomer for polyester and polyamide [2, 7]. For example, poly(ethylene 2,5-furandicarboxylate)
(PEF) [8] is being further developed and commercialized in beverage package for its excellent mechanical and barrier properties. PBF material has largely reduced carbon dioxide permeability $(19 \times)$ and diffusivity $(31 \times)$ compared to the respective properties of PET [9]. Other polyesters like poly(butylene 2,5-furandicarboxylate) (PBF) [10], poly(butylene adipate-co-butylene 2,5-furandicarboxylate) (PBAF) [11] and poly(butylene succinic-co-butylene 2,5-furandicarboxlylate) (PBSF) [12] with satisfying thermomechanical properties were also successfully prepared. PBF has high tendency to crystallize and allows the continuous fibers to be drawn from melt. The crystalline structure of PBF is analogous with that of PBT, which contains crystalline states of $\alpha$-phase (more stable) and $\beta$-phase (less stable) [10]. As for furanicaliphatic coplyesters like PBSF and PBAF, the main

*Corresponding author, e-mail: jhji@mail.ipc.ac.cn (C) BME-PT 
advantage is that they display enhanced biodegradability compared with neat PBF. They were random copolymers whose composition was well controlled by the feed ratio of the diacid monomers. The ability of the copolymer to crystallize was drastically reduced with the addition of the comonomer and consequently increase of the elongation at break of the polymer [13]. These FDCA based polyesters have shown great prospective to replace their petroleumbased counterparts applied as plastic products $[3,8]$. However, the synthesis of FDCA based polyesters applied as thermoplastic elastomers has rarely been reported.

Thermoplastic polyester elastomer (TPEE) [14] is receiving increasing attention for its facile processability, good recyclability and tunable elasticity. TPEE usually contains repeating high-melt blocks that are capable of crystallization (hard segments), and amorphous blocks with a relatively low glass transition temperature (soft segments). Typically, hard segments are composed of multiple short-chain ester units such as butylene terephthalate units [15] whereas the soft segments are derived from aliphatic polyether and polyester glycols [16]. TPEE elastomers are easy to be synthesized and processed as general thermoplastic polyesters. Specifically, they can be prepared by esterification and polycondensation and processed by conventional methodologies like injection molding, compression and transfer molding. Several TPEE products like Hytrel ${ }^{\circledR}$ (Du Pont), Pelprene ${ }^{\circledR}$ (GAF Corporation) and Ecdel ${ }^{\circledR}$ (Eastman Chemical Co.) have been commercialized, demonstrating high strength, high elasticity, excellent dynamic properties and creep resistance. These TPEE elastomers find various applications in gears, cable covers, and medicine packages, etc. However, the hard segments of all these commercial TPEE, butylene terephthalate, are closely dependent of petroleum supply.

To meet the requirement of sustainable development of polymer industry, bio-based and biodegradable elastomers need to be developed to fulfill a biocycle in nature. For example, long-chain aliphatic dicarboxylic acids (C23 $\alpha, \omega$-dicarboxylic acid) and diols were used for the generation of all-aliphatic thermoplastic polyester elastomers. The entire length of the plant oil fatty acids serves as hard segments, which exploits polyethylene-like crystallinity for physical crosslinking [17]. Aromatic-aliphatic polyester elastomer is also prepared to obtain better mechanical strength and thermal stability. Poly(trimethylene 2,5-furandicarboxylate-block-dimerized fatty acid) (PTF- $b$-FADD) copolymers was synthesized fully based on plant-derived reagents. Thermal and mechanical properties of this randomly distributed multi-blocked copolyester were governed by PTF to FADD ratio [18]. Similarly, butylene 2,5-furandicarboxylate units substituted their terephthalate counterparts to serve as a bio-based hard segments for elastomer [19]. The biodegradability is another advantage which can be achieved by introducing suitable aliphatic comonomers to the aromatic polyester elastomer [20]. It has been proposed that the ensuing aliphatic ester linkages are vulnerable to enzyme attacks due to increased water uptake. Among aliphatic moieties, $\varepsilon$-caprolactone polyester diol can act as promising soft segments for chain mobility and nontoxicity [21]. It should be noted that the incorporation of $\varepsilon$-caprolactone polyester diol can be simply achieved by using easily-accessible monomer $\varepsilon$-caprolactone, instead of high-price $\varepsilon$-caprolactone polyester diol. Thereby the furanic-aliphatic copolyester elastomer will possess original feature of high strength and biodegradability stemming from the uses of aromatic and aliphatic monomers respectively.

In this work, poly(butylene 2,5-furandicarboxylate$\varepsilon$-caprolactone) (PBFCL) copolyester based on monomers of 2,5-furandicarboxylic acid, 1,4-butanediol and $\varepsilon$-caprolactone, was prepared for the first time. With biodegradability and high strength inherited from CL and FDCA monomers, the PBFCL polyester elastomer presented here could be a promising candidate in applications such as furniture industry, sporting goods or even medical area. PBFCL was characterized with respect to chemical structure, thermal and mechanical properties, and enzymatic degradability.

\section{Experimental section \\ 2.1. Materials}

2,5-Furandicarboxylic acid (FDCA, 99.5\%) was kindly provided by Ningbo Biomass \& Biotechnology Co., Ltd. (Ningbo, China). 1,4-Butanediol (BDO, 99.5\%) and $\varepsilon$-caprolactone (CL, 99\%) were purchased from Aladdin Reagent Co., Ltd. (Shanghai, China). Titanium tetraisopopoxide ( $\mathrm{Ti}(\mathrm{OiPr})_{4}, 98 \%$ ), antimony acetate $\left(\mathrm{Sb}(\mathrm{Ac})_{3}, 97 \%\right)$, chloroform $\left(\mathrm{CHCl}_{3}, 99 \%\right)$ and trifluoroacetic acid $\left(\mathrm{C}_{2} \mathrm{HF}_{3} \mathrm{O}_{2}, 99.9 \%\right)$ were purchased from J\&K Scientific Ltd. (Beijing, China). 
$\mathrm{Ti}(\mathrm{OiPr})_{4}$ and $\mathrm{Sb}(\mathrm{Ac})_{3}$ were used as catalysts, and $\mathrm{CHCl}_{3}$ and $\mathrm{C}_{2} \mathrm{HF}_{3} \mathrm{O}_{2}$ were used as solvents. All chemicals were used as received without purifying.

\subsection{Polymerization procedure}

PBFCL was synthesized by the combination of esterification, ring-opening reaction and polycondensation. The one-pot reaction was performed in a fourheaded reactor equipped with a mechanical stirrer, a nitrogen inlet, a thermometer, and a condenser. Furanic $\alpha-\omega$ hydroxyl oligomers were prepared from monomers of FDCA and BDO via esterification reaction as previously reported. FDCA and 1,4-butanediol with the mole ratio of 1 to 3 were charged into the reaction flask. A predetermined volume of catalyst solution $\left(10 \mathrm{mg} / \mathrm{mL} \mathrm{Ti}(\mathrm{OiPr})_{4}\right.$ in 1,4-butanediol) was transferred into the reaction flask. The reaction flask was first heated to $190^{\circ} \mathrm{C}$ for $2 \mathrm{~h}$, and then heated to $220^{\circ} \mathrm{C}$ within $4 \mathrm{~h}$ to complete the first stage reaction [22]. In the second stage, $\mathrm{CL}$ and $\mathrm{Sb}(\mathrm{Ac})_{3}(0.1 \mathrm{~mol} \% \mathrm{CL})$ were added to the system to proceed ring-opening reaction initiated by the furanic $\alpha-\omega$ hydroxyl oligomers at the temperature of $200^{\circ} \mathrm{C}$ and nitrogen atmosphere. The ring-opening reaction was proceeded for about 3 hours [9]. After that, the polycondensation reaction was conducted by increasing the temperature to $240{ }^{\circ} \mathrm{C}$ and reducing the pressure lower than $100 \mathrm{~Pa}$. PBFCLs with different CL contents were obtained by controlling the weight ratio of $\varepsilon$-caprolactone to furanic $\alpha-\omega$ hydroxyl oligomers in feed. Resulting copolyesters were purified by dissolving in trifluoroacetic acid and then precipitated in cold methanol.

\subsection{Characterization}

Molecular weight was determined by gel permeation chromatography (GPC, Waters 1515, USA). Chloroform was used as eluent and polystyrene standards for calibration. The concentration of sample solution was about $1 \mathrm{mg} / \mathrm{mL}$, and the flow rate of eluent was $1 \mathrm{~mL} / \mathrm{min}$.

${ }^{1} \mathrm{H}$ NMR spectra were recorded on an NMR spectrometer (Bruker Avance 400, Switzerland) and deuterated trifluoroacetic acid was used as solvent. The concentration of each sample solution was about $15 \mathrm{mg} / \mathrm{mL}$.

$\mathrm{X}$-ray diffraction (XRD) pattern was recorded on a diffractometer (Bruker D8 Focus, Switzerland) using $\mathrm{Cu}-\mathrm{K} \alpha$ radiation. Samples were first scanned in $2 \theta$ from 5 to $60^{\circ}$ at a fast speed of $0.5^{\circ} / \mathrm{s}$ and then from 15 to 30 at a low speed of $0.02 \%$.

Thermal transitions were measured on a differential scanning calorimeter (DSC, Mettler-Toledo DSC 1, Switzerland). Two heating/cooling cycles were performed from -80 to $200^{\circ} \mathrm{C}$ under nitrogen atmosphere. The heating and cooling rates were both $10^{\circ} \mathrm{C} / \mathrm{min}$.

Thermal stability was measured on a thermogravimetric analyzer (TGA, TA Q50, USA). The samples were heated from 25 to $600{ }^{\circ} \mathrm{C}$ at $10^{\circ} \mathrm{C} / \mathrm{min}$ under nitrogen atmosphere.

Viscoelastic behavior was assessed on a dynamic mechanical analyzer (DMA, Mettler-Toledo DMA/ SDTA861e, Switzerland). Samples were molded into rectangular bars $\left(9 \times 5 \times 0.7 \mathrm{~mm}^{3}\right)$ and tested from -80 to $65^{\circ} \mathrm{C}$ at a heating rate of $10^{\circ} \mathrm{C} / \mathrm{min}$ and frequency of $1 \mathrm{~Hz}$ respectively under a tension mode.

Mechanical property was performed on a tensile testing machine (Instron 5966, USA). Samples were molded into dumbbell shaped specimens $\left(25 \times 4 \times 2 \mathrm{~mm}^{3}\right)$ and tested at crosshead speed of $50 \mathrm{~mm} / \mathrm{min}$.

Biodegradable properties were determined using enzymatic degradation experiment. Samples were hotpressed into square shaped films and immersed at $37^{\circ} \mathrm{C}$ in phosphate buffer solution $(\mathrm{pH}=7.2)$ with $1 \mathrm{mg} / \mathrm{mL}$ lipases from porcine pancreas. Morphologies of samples during certain intervals of degradation were recorded on a field emission scanning electron microscope (FE-SEM, Quanta 250 FEG, USA).

\section{Results and discussion}

\subsection{Synthesis and chemical structure}

PBFCL was obtained by a facile procedure combined of esterification, ring-opening reaction and polycondensation (Figure 1). Detailed synthesis procedure is described in the experimental section. Samples are named as PBFCL-20, PBFCL-30, PBFCL40, PBFCL-50 and PBFCL-60 according to weight percentage of $\varepsilon$-caprolactone. As shown in Table 1, the actual composition of the resultant copolyester could be controlled by the feed ratio of FDCA to CL monomers. The PDI is among 2.11 to 3.49 and the broad polymer diversity is ascribed to the existence of impurities in bio-based FDCA and decarboxylation of 2,5-FDCA under reaction conditions [13]. The weigh-average molecular weights of obtained PBFCL samples are among 8.05 to $40.7 \mathrm{~kg} / \mathrm{mol}$. The molecular weight decreases with increasing CL content, 


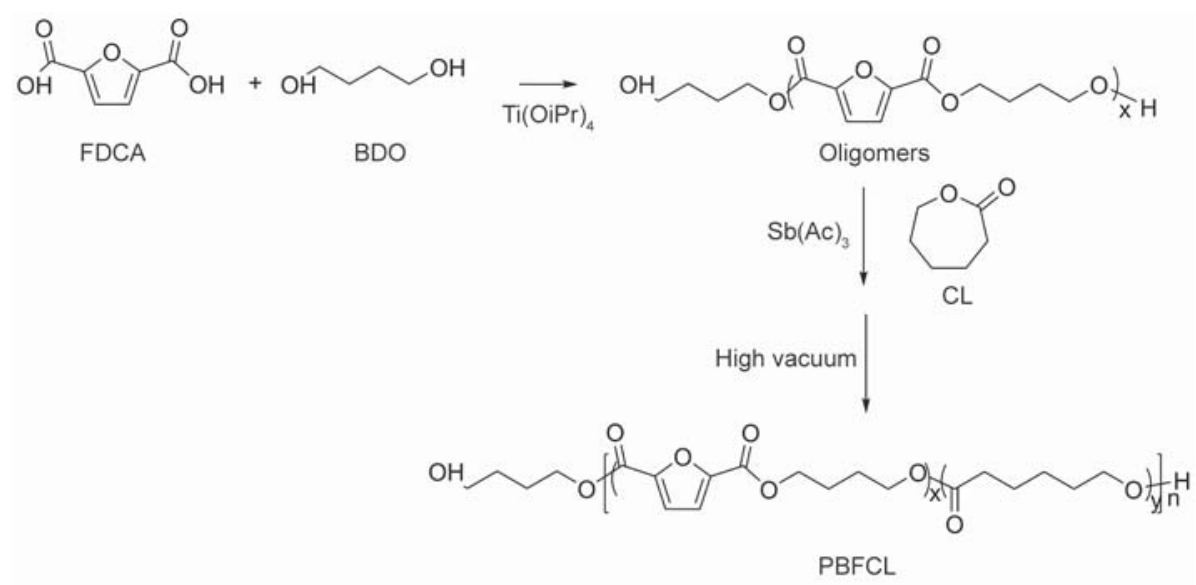

Figure 1. Synthesis procedure of PBFCL from monomers of FDCA, BDO, and CL

indicating that compared with furanic $\alpha$ - $\omega$ hydroxyl oligomers, CL monomer is more difficult than furanic $\alpha-\omega$ hydroxyl oligomers to be introduced to the copolyester chain. This is also verified by the lower CL content in actual composition than in feed ratio.

Table 1. Molecular characterization of PBFCL copolyesters

\begin{tabular}{|c|c|c|c|c|}
\hline \multirow{2}{*}{ Sample } & \multicolumn{2}{|c|}{$\begin{array}{c}\text { CL } \\
{[\mathbf{m o l} \% \mathbf{l}}\end{array}$} & \multicolumn{2}{c|}{ GPC results } \\
\hline & Feed $^{\mathbf{a}}$ & $\mathbf{1}^{\mathbf{H}} \mathbf{N M R}^{\mathbf{b}}$ & $\begin{array}{c}\boldsymbol{M}_{\mathbf{w}} \cdot \mathbf{1 0}^{\mathbf{3}} \\
{\left[\mathbf{g} / \mathbf{m o l}^{\mathbf{3}}\right]}\end{array}$ & PDI \\
\hline PBFCL-20 & 36 & 32 & 40.7 & 3.49 \\
\hline PBFCL-30 & 54 & 49 & 42.3 & 2.57 \\
\hline PBFCL-40 & 60 & 53 & 18.5 & 2.53 \\
\hline PBFCL-50 & 67 & 65 & 15.0 & 2.32 \\
\hline PBFCL-60 & 73 & 66 & 8.05 & 2.11 \\
\hline
\end{tabular}

${ }^{\mathrm{a}}$ Molar percentage of CL to the total of CL and FDCA calculated on feed. ${ }^{b}$ Molar percentage of CL to the total of CL to FDCA calculated on integral area in ${ }^{1} \mathrm{H}$ NMR spectra.
The lower reactivity of $\varepsilon$-caprolactone probably arises from inadequacy of diol initiator during the ringopening reaction and elimination of $\varepsilon$-caprolactone at high temperature during the polycondensation reaction, as also can be seen in the case of copolymers of TPA and $\varepsilon$-caprolactone [23].

Chemical structure and the real composition of PBFCL were confirmed by ${ }^{1} \mathrm{H}$ NMR analysis, as seen in Figure 2. Peaks at $7.42 \mathrm{ppm}$ (a), $4.58 \mathrm{ppm}$ (b) and $2.08 \mathrm{ppm}(\mathrm{g})$ should be attributed to furan nucleus and protons of $\mathrm{BDO}$ in $\mathrm{BF}$ segments, which is in accordance with spectrum of PBF [9]. Similarly, peaks at $4.28 \mathrm{ppm}(\mathrm{e}), 2.54 \mathrm{ppm}(\mathrm{f}), 1.80 \mathrm{ppm}(\mathrm{h})$, and $1.52 \mathrm{ppm}$ (i) are assigned to methylene protons of $-\mathrm{CH}_{2}-\mathrm{O}-,-\mathrm{OC}-\mathrm{CH}_{2}-$, and $-\left(\mathrm{CH}_{2}\right)_{3}-$ in CL segments [24]. The signals at $4.52 \mathrm{ppm}$ (c) and $4.34 \mathrm{ppm}$ (d) are also observed. These two peaks are related to

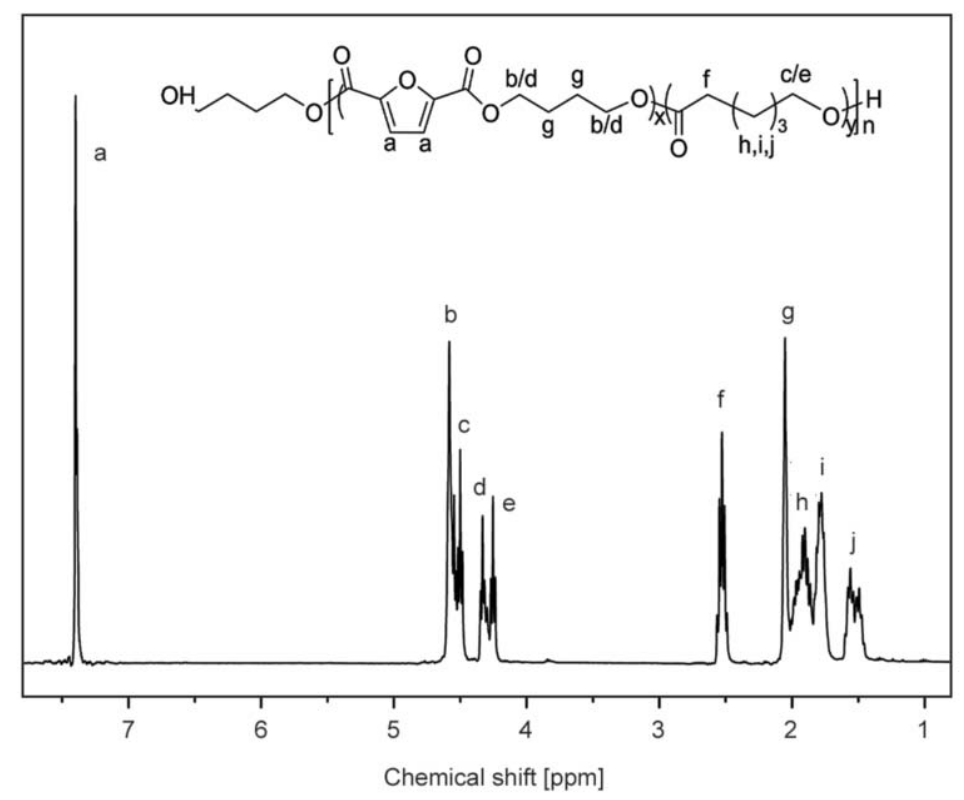

Figure 2. ${ }^{1} \mathrm{H}$ NMR spectra of PBFCL 
Table 2. Proportion of F-B, F-CL, CL-B, CL-CL diads in PBFCL/1-5 based on ${ }^{1} \mathrm{H}$ NMR analysis

\begin{tabular}{|l|c|c|c|c|c|}
\hline \multicolumn{1}{|c|}{ Proportion } & PBFCL-20 & PBFCL-30 & PBFCL-40 & PBFCL-50 & PBFCL-60 \\
\hline F-B & 0.672 & 0.480 & 0.451 & 0.335 & 0.264 \\
\hline F-CL & 0.148 & 0.199 & 0.219 & 0.201 & 0.270 \\
\hline CL-B & 0.132 & 0.182 & 0.163 & 0.227 & 0.238 \\
\hline CL-CL & 0.048 & 0.139 & 0.167 & 0.237 & 0.228 \\
\hline
\end{tabular}

methylene protons of CL neighboring FDCA ester group and methylene protons of BDO bonded to $\varepsilon$ caprolactone ester group respectively. These observations confirm that $\varepsilon$-caprolactone and furanic $\alpha-\omega$ hydroxyl functionalized oligomers were introduced to the copolyester successfully and expected polymerization reactions took place.

A deeper inspection of ${ }^{1} \mathrm{H}$ NMR results reveals the chemical chain structure of PBFCL via integration area calculation. It is well acknowledged that transesterification during melt polycondensation could result in complex chain structure of PBFCL. Linkages between FDCA, BDO, and CL units are not unique and the structure of CL is asymmetrical. Therefore, instead of calculating the sequence length of each segments, herein we focus on how FDCA, BDO, and CL units are preferentially linked [25], which is associated with the proportion of each integration area of methylene proton attached to ester groups $(\delta \approx$ $4.58,4.52,4.34$ and 4.28 ppm respectively) of all diads, viz., F-B, F-CL, CL-B, and CL-CL (Table 2). In all PBFCL, sequence length of both hard (BF segments) and soft segments (CL segments) are short, indicated by large proportion of F-CL and CL-B diads. For one thing, as $\mathrm{CL}$ content increases, proportion of F-B diads declines and sequence length of BF segments (hard segments) decreases. The increasing proportions of F-CL and CL-B diads demonstrate that BF segments are disturbed by CL units. For another, sequence length of CL segments does not increase significantly with adequate increment of CL content. We propose that BF segments act as hard segments providing thermally-reversible physical crosslinks while CL segments soft segments ensuring flexibility. In conclusion, PBFCL is multi-blocked copolyester with randomly distributed rigid and soft segments.

\subsection{Crystallization}

XRD patterns were investigated to assess the crystallization part of PBFCL. In a fast-speed scan mode as shown in Figure 3a, PBFCL-20, PBFCL-30 and PBFCL-40 are all semi-crystalline polymers showing peaks at $2 \theta=18.9,22.4$, and $25.0^{\circ}$. Those peaks are same in the same position as PBF homopolymer [9], confirming that PBFCL and PBF share the same crystalline structure formed by BF segments. Crystallinity of PBFCL decreases with increasing CL content owning to shorter sequence length of $\mathrm{BF}$ segments. Particularly, PBFCL-50 and PBFCL-60 both show smooth lump and crystalline peaks are difficult to detect. In order to assess the crystallinity of CL segments, a slow-speed scan on XRD was conducted, as shown in Figure 3b. Magnification of PBFCL-40 and PBFCL-60 patterns in the range of $2 \theta$ from 17 to $26^{\circ}$ are depicted in Figure $3 \mathrm{c}$ and $3 \mathrm{~d}$ to give a further inspection. Actually, all PBFCL show extreme small peaks at 21.5 and $23.8^{\circ}$, indicating very weak crystalline of CL segments. Actually, long CL segments in PCL have a strong tendency to crystallize while most CL segments in PBFCL are too short to crystallize. In conclusion, BF segments form crystalline domains as physical crosslinks while CL segments form amorphous phase to provide flexibility.

\subsection{Thermal properties}

DSC curves (Figures $4 \mathrm{a}$ and $4 \mathrm{~b}$ ) demonstrate thermal transition behaviors of PBFCL during the first and second heating scan at a rate of $10^{\circ} \mathrm{C} / \mathrm{min}$. In the first run, PBFCL-20, PBFCL-30 and PBFCL-40 all exhibit two separate melting points. The melting point around $44^{\circ} \mathrm{C}$ is associated with CL segments and another higher one is related to BF segments. Specially, PBFCL-30 and PBFCL-40 don't show the higher melting point in the second heating run because the standard cooling rate $\left(10^{\circ} \mathrm{C} / \mathrm{min}\right)$ is too fast for the BF segments to fully crystallize before the glass transition temperature.

Detailed data of glass transition temperature $\left(T_{\mathrm{g}}\right)$, melting temperature $\left(T_{\mathrm{m}}\right)$, and melting enthalpy $\left(\Delta H_{\mathrm{m}}\right)$ are listed in Table 3. The presence of soft CL segments plasticizes the polymer chains, which contributes to lower $T_{\mathrm{g}}$ as compared to PBF. It's obvious that the $T_{\mathrm{g}}$ decreases with increasing content of CL segments, which promotes the chain mobility of PBFCL. With tunable $T_{\mathrm{g}}$ controlled by the ratio of BF segments to CL segments, PBFCL can therefore be 

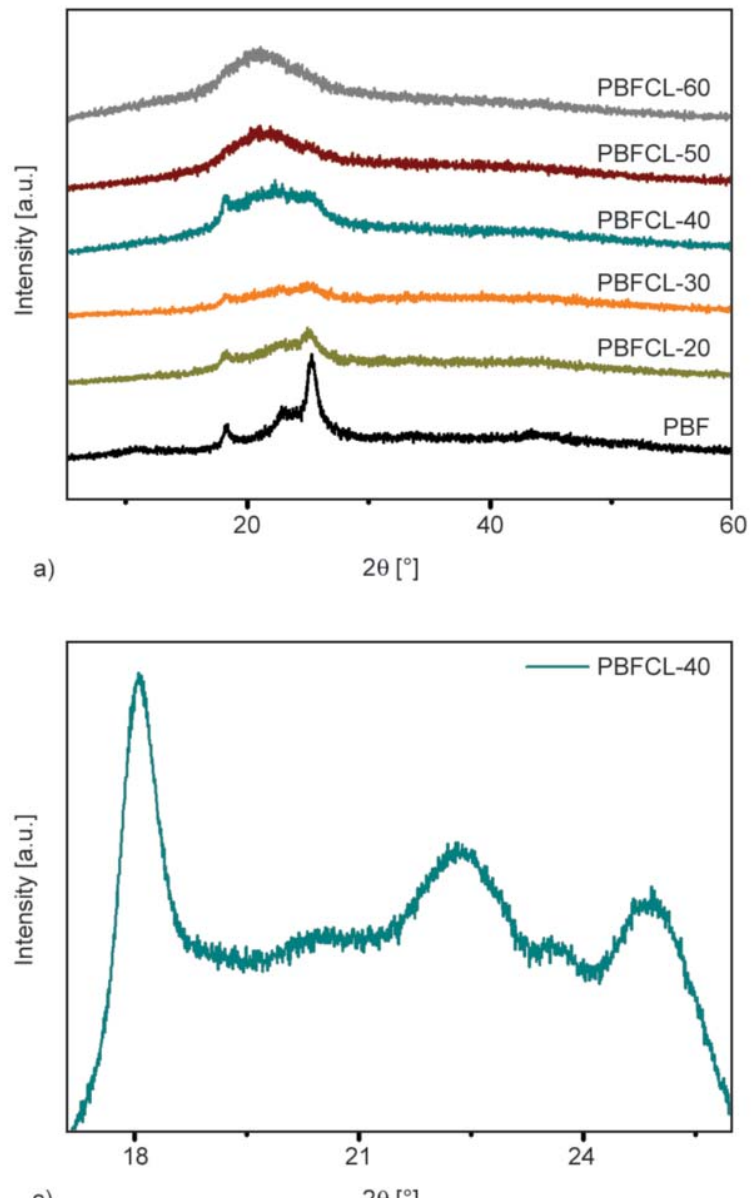
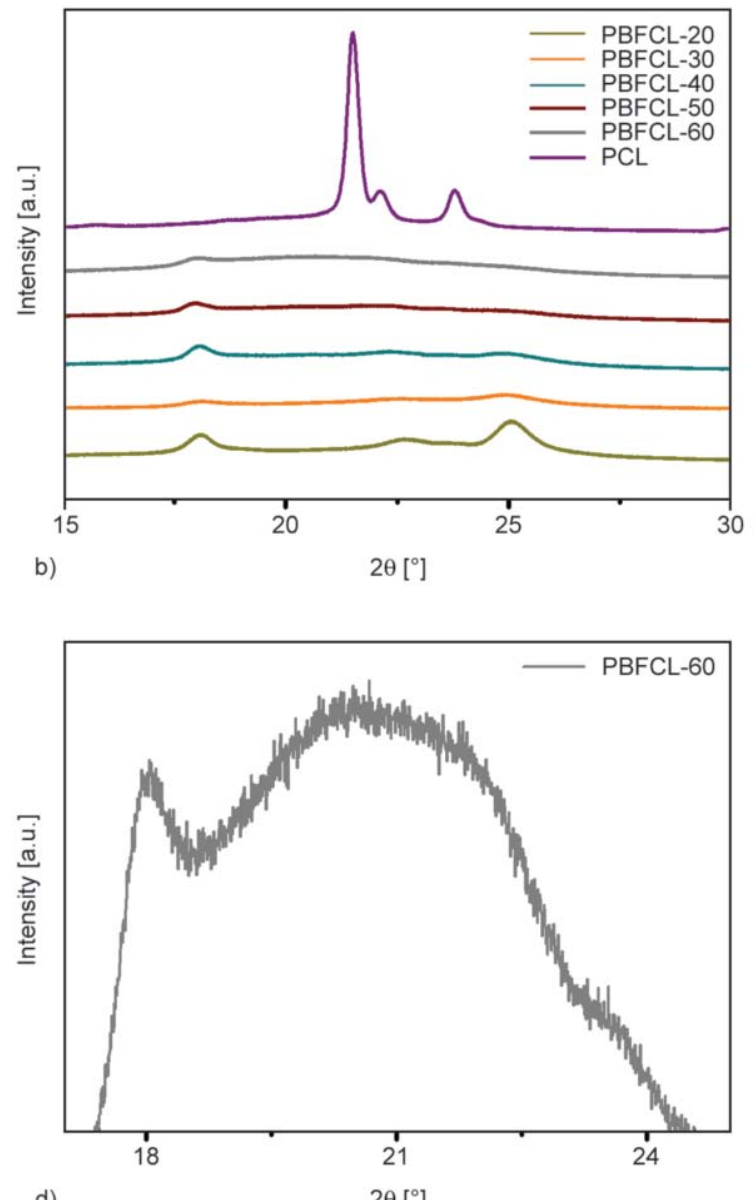

d)

Figure 3. XRD pattern of PBFCL in (a) fast-speed scan and (b) slow-speed scan; magnification of (c) PBFCL-40 and (d) PBFCL-60

used at different temperatures. Apparently, as CL content increases, $T_{\mathrm{m}, 1}$ and $\Delta H_{\mathrm{m}, 1}$ decrease and finally corresponding melting signals disappear resulting from the shorter segmental length of BF segments and subsequent weaker crystallization. Therefore, temperature application window decided by $T_{\mathrm{g}}$ and $T_{\mathrm{m}}$ can be tunable with respect to various demands. On the other hand, $\triangle H_{\mathrm{m}}$ of CL segments in all PBFCL can be ignored because the crystalline of CL segments is rather weak, which is consistent with XRD results.

Figure 4c shows TGA traces of PBFCL and their thermal degradation behavior is quite similar. Obviously, thermal degradation doesn't take place until $300^{\circ} \mathrm{C}$, which is much higher than $T_{\mathrm{m}}$. That is to say, PBFCL can be processed in molten state without any thermal degradation. The decomposition temperature at 5\% weight loss $\left(T_{\mathrm{d}, 5 \%}\right)$ and at maximum rate $\left(T_{\mathrm{d}, \max }\right)$ listed in Table 3 are applied to evaluate their thermal stabilities. $T_{\mathrm{d}, 5 \%}$ of PBFCL increases with arising furanic moieties, suggesting that the existence of aromatic furanic units (BF) in the copolyester chain promotes thermal stability. All in all, PBFCL demonstrates excellent thermal stability, which is comparable or even better than those of aliphatic polyesters $[26,27]$.

DMA analysis, a normally used technique in the detection of polymer relaxation, confirms the presence of one clear relaxation of all PBFCL on tan $\delta$ graphs (Figure 4d). The peak in each curve is attributed to $\alpha$-transition (glass transition) of amorphous continuous phase. These only relaxation shows that soft and hard segments are well compatible and their sequence length are both not very long. All PBFCL have relatively low glass transition temperature and are elastic at room temperature. Value of $\tan \delta$ after glass transition indicates component of elastic strain in PBFCL. For PBFCL-20, PBFCL-30 and PBFCL$40, \tan \delta$ curves show relatively low platform after glass transition, implying more component of elastic strain. They tend to rebound when extended and the resilience is provided by the crystalline phase formed by $\mathrm{BF}$ hard segments. Meanwhile, $\tan \delta$ curves of PBFCL-50 and PBFCL-60 show relatively high 

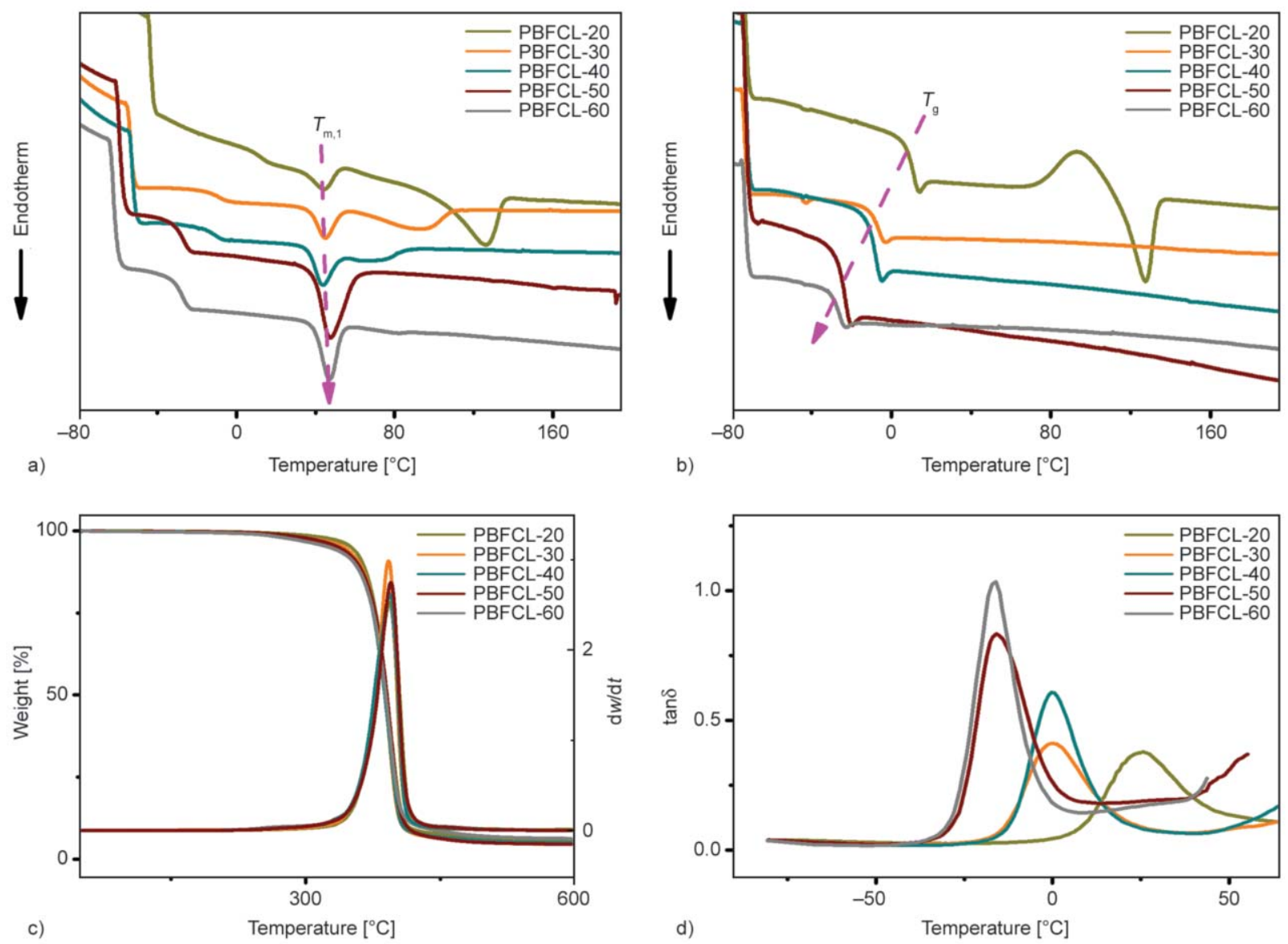

Figure 4. DSC thermograms recorded for PBFCL during (a) first heating and (b) second heating scan; (c) TGA traces of PBFCL; (d) Loss factor tan $\delta$ curves of PBFCL tested on DMA

Table 3. DSC and TGA results of PBFCL

\begin{tabular}{|c|r|c|c|c|c|c|c|}
\hline Sample & $\begin{array}{c}\boldsymbol{T}_{\mathbf{g}} \\
{\left[{ }^{\circ} \mathbf{C}\right]}\end{array}$ & $\begin{array}{c}\boldsymbol{T}_{\mathbf{m}, \mathbf{1}} \\
{\left[{ }^{\circ} \mathbf{C}\right]}\end{array}$ & $\begin{array}{c}\boldsymbol{T}_{\mathbf{m}, \mathbf{2}} \\
{\left[{ }^{\circ} \mathbf{C}\right]}\end{array}$ & $\begin{array}{c}\Delta \boldsymbol{H}_{\mathbf{m}, \mathbf{1}} \\
{[\mathbf{J} / \mathbf{g}]}\end{array}$ & $\begin{array}{c}\Delta \boldsymbol{H}_{\mathbf{m}, \mathbf{2}} \\
{[\mathbf{J} / \mathbf{g}]}\end{array}$ & $\begin{array}{c}\boldsymbol{T}_{\mathbf{d}, \mathbf{5} \%} \\
{\left[{ }^{\circ} \mathbf{C}\right]}\end{array}$ & $\begin{array}{c}\boldsymbol{T}_{\mathbf{d}, \mathbf{m a x}} \\
{\left[{ }^{\circ} \mathbf{C}\right]}\end{array}$ \\
\hline PBFCL-20 & 7.2 & 44.1 & 125.9 & 7.70 & 22.50 & 351 & 394 \\
\hline PBFCL-30 & -8.3 & 44.9 & 93.9 & 5.61 & 10.40 & 343 & 392 \\
\hline PBFCL-40 & -12.6 & 43.6 & 73.3 & 4.53 & 2.13 & 335 & 394 \\
\hline PBFCL-50 & -24.4 & 43.6 & - & 9.60 & - & 337 & 395 \\
\hline PBFCL-60 & -29.5 & 44.3 & - & 5.00 & - & 327 & 393 \\
\hline
\end{tabular}

plateau after glass transition, manifesting less component of elastic strain and lack of crystalline domains. Thereby, the molecular chains of PBFCL-50 and PBFCL-60 are easy to flow when extended other than rebound.

\subsection{Mechanical properties}

Typical tensile stress-strain curves before breaking are depicted in Figure 5a. PBFCL-20 behaves as a typical semi-crystalline hard thermoplastic, showing a distinct yielding point before breaking. PBFCL of other compositions act as typical elastomers. They do not show the necking effect during the deformation, and samples get thinner uniformly in the whole volume. Especially, excellent resilience of PBFCL-30 and PBFCL-40 after breaking was observed, due to the physical crosslinks formed by BF crystalline domains. The stress-strain curves in the initial stage of tensile test is depicted in Figure 5b. Furanic moieties provide additional stiffness to a polymeric chain, and hence PBFCL with more BF moieties have higher Young's modulus.

Young's modulus, tensile strength and elongation at break of PBFCL are listed in Table 4. Modulus and strength increase while elongation decrease with increasing BF contents. On one hand, furanic moieties ensure improved stiffness and strength of PBFCL elastomer during deformation but a further increase tends to result in hard plastic formation. On the other hand, CL moieties provides chain mobility of PBFCL and therefore modulus and strength decrease while elongation increase with CL content. Among all the five compositions of PBFCL, PBFCL-40 shows best comprehensive performance when applied as high performance elastomer. To be specific, its Young's modulus is as low as $15.4 \mathrm{MPa}$, tensile strength is as high $24.8 \mathrm{MPa}$, and elongation as much as $885 \%$. Moreover, mechanical properties of the copolyester 

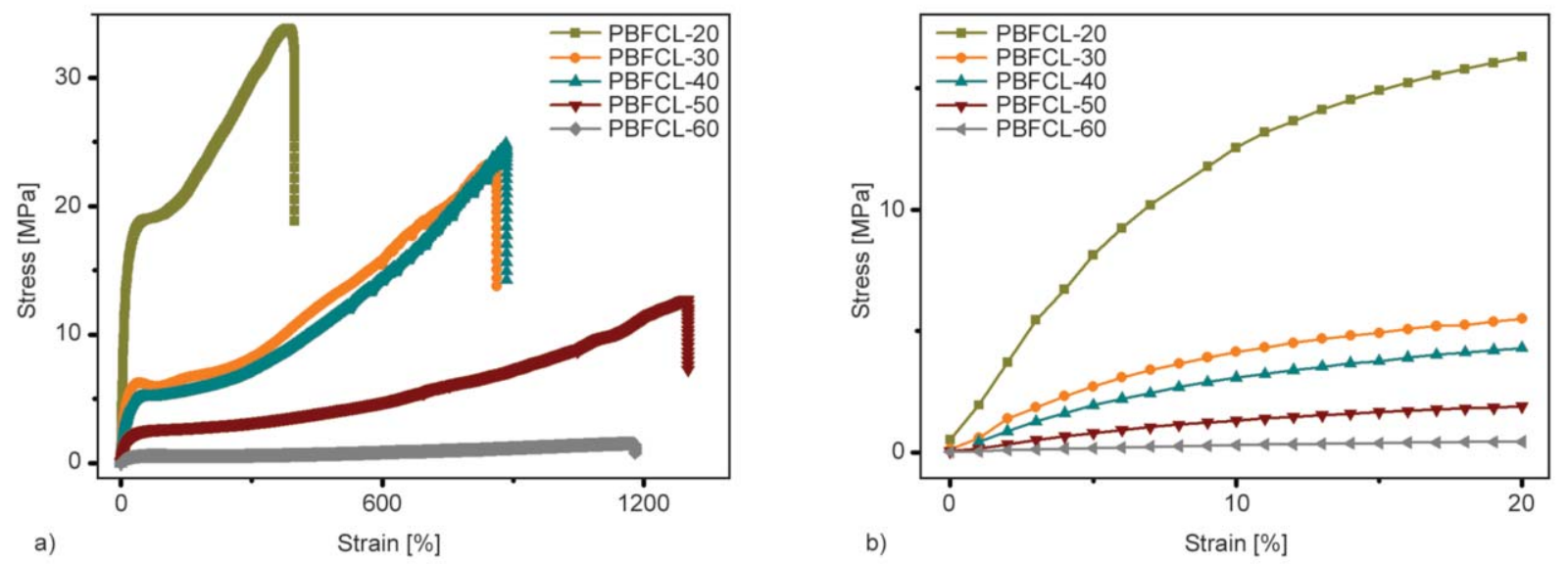

Figure 5. Stress $(\sigma)$-strain $(\varepsilon)$ curves of PBFCL (a) before breaking and (b) in the initial stage of tensile test

Table 4. Young's modulus, tensile strength and elongation at break of PBFCL

\begin{tabular}{|c|c|c|c|c|}
\hline Sample & $\begin{array}{c}\boldsymbol{E} \\
{[\mathbf{M P a}]}\end{array}$ & $\begin{array}{c}\boldsymbol{\sigma}_{\mathbf{m}} \\
{[\mathbf{M P a}]}\end{array}$ & $\begin{array}{c}\boldsymbol{\varepsilon}_{\mathbf{b}} \\
{[\mathbf{\%}]}\end{array}$ & $\begin{array}{c}\text { Yield } \\
{[\mathbf{\%}]}\end{array}$ \\
\hline PBFCL-20 & 188.00 & 33.8 & 398 & 60 \\
\hline PBFCL-30 & 57.70 & 23.3 & 862 & - \\
\hline PBFCL-40 & 15.40 & 24.8 & 885 & - \\
\hline PBFCL-50 & 5.08 & 12.7 & 1300 & - \\
\hline PBFCL-60 & 3.79 & 1.55 & 1180 & - \\
\hline
\end{tabular}

elastomer could be finely tuned by incorporating different BF contents. In all, PBFCL elastomer outcompetes other aliphatic polyester elastomers [28, 29] for its increased toughness derived from rigid furanic moieties.

\subsection{Enzymatic degradation}

Biodegradation is an attractive aspect of research efforts in thermoplastic elastomer. A good combination of biodegradation with mechanical properties is highly desirable for practical application. Inspired by this, enzymatic degradation experiment was conducted to assess the biodegradability of PBFCL. Surface morphologies of samples during enzymatic degradation at several intervals are shown in Figure 6. They all display smooth surface before enzymatic degradation. Different depth and size of pitting and erosion on the surfaces indicates different degradation rates. For PBFCL-20, PBFCL-30 and PBFCL-40, the surfaces firstly becomes rough, and tiny and shallow pits are presented at specific areas at $14^{\text {th }}$ day, then holes extend in size and depth as degradation proceeds further at $28^{\text {th }}$ day. For PBFCL-50 and PBFCL-60, greater surface changes and more apparent degradation are presented. Firstly small apparent fragments are shown and enzymatic erosion occurs on surface, then films begin to disintegrate as large cracks appear. The results show that the enzyme preferentially hydrolyze PBFCL with more CL moieties but is active on all tested subtracts. It is CL segments that ensure the biodegradability of PBFCL because aliphatic amorphous phase is extremely vulnerable to enzymatic attack and then degrades fast. On the other hand, degradation is hampered by crystalline parts of polymer, which make water and enzyme penetration in film matrix inaccessible [30].

\section{Conclusions}

Bio-based and biodegradable PBFCL was successfully prepared from monomers of 2,5-furandicarboxylic acid, 1,4-butanediol, and $\varepsilon$-caprolactone via a procedure combined of esterification, ring-opening reaction and polycondensation. In this copolyester elastomer, BF hard segments crystallize to serve as physical crosslinks where CL soft segments provide flexibility. Introduction of aromatic furanic moieties impart PBFCL with superior thermal stability and tensile strength, while aliphatic CL segments guarantee the biodegradability of PBFCL. An important aspect of these new furanic-aliphatic polyesters is their tailor-made properties simply achieved by incorporating different $\varepsilon$-caprolactone contents. Typically, PBFCL-40 of optimal composition has Young's modulus as low as $15.4 \mathrm{MPa}$, tensile strength as high $24.8 \mathrm{MPa}$, and elongation is $885 \%$. We also expect a further enhancement in mechanical performance upon optimization of synthesis parameters and polyester composition. 


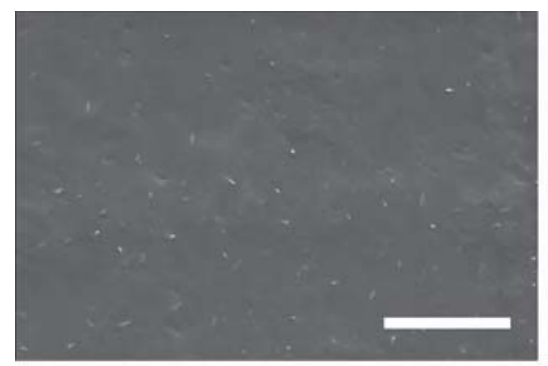

$\left.a_{1}\right)$

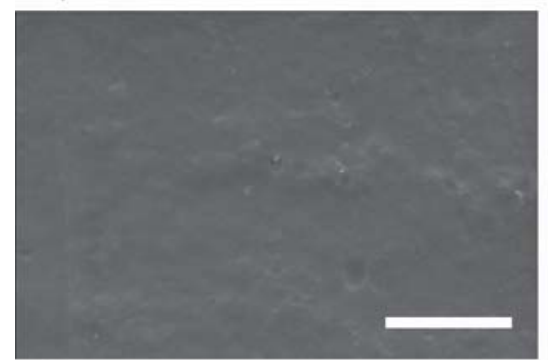

$\left.b_{1}\right)$

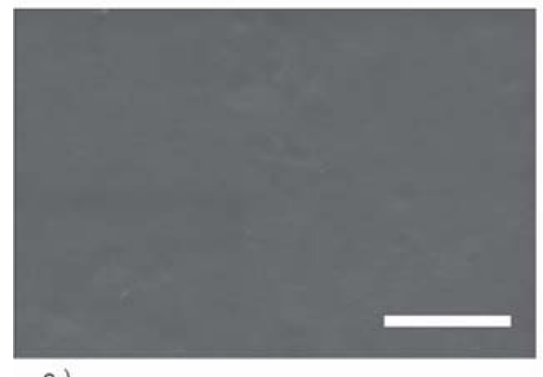

$\left.c_{1}\right)$

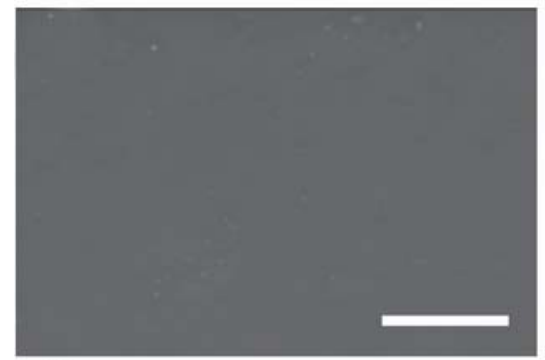

$\left.d_{1}\right)$

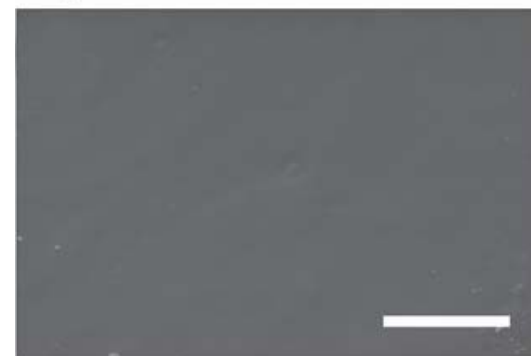

$\left.e_{1}\right)$

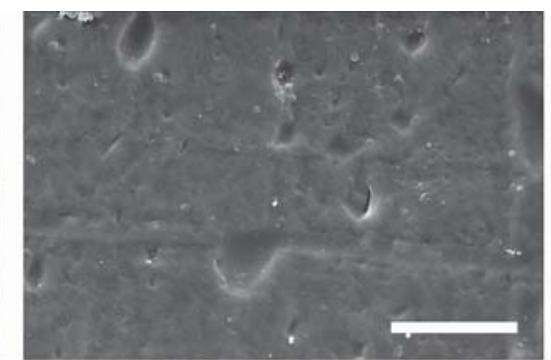

$\left.a_{2}\right)$

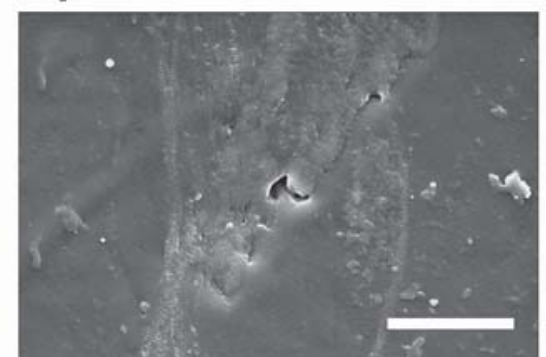

$\left.b_{2}\right)$

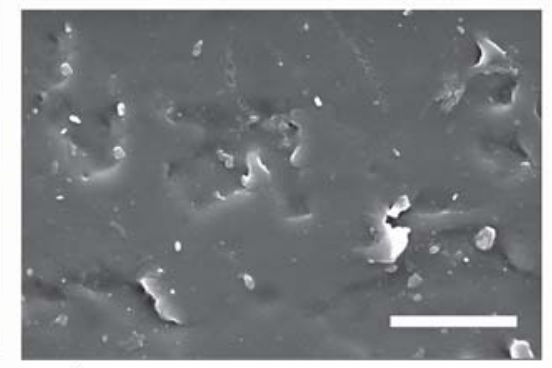

$c_{2}$ )

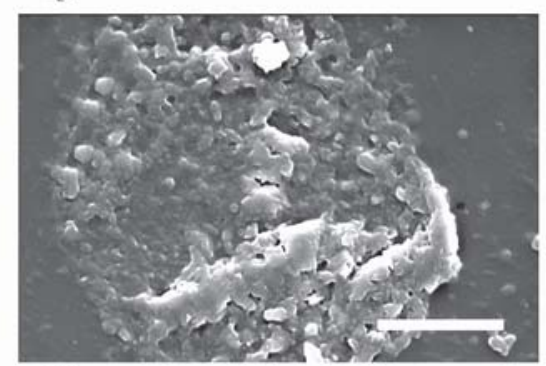

$d_{2}$ )

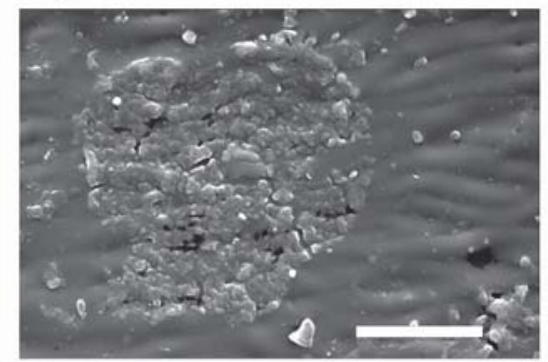

$e_{2}$ )

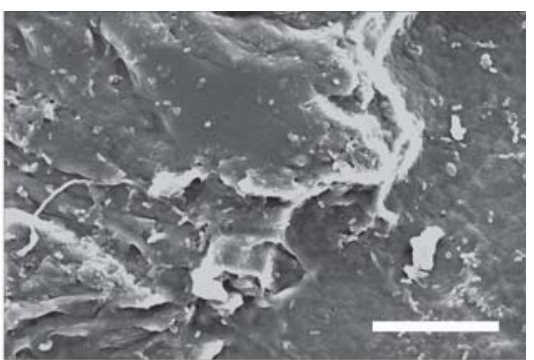

$\left.\mathrm{a}_{3}\right)$

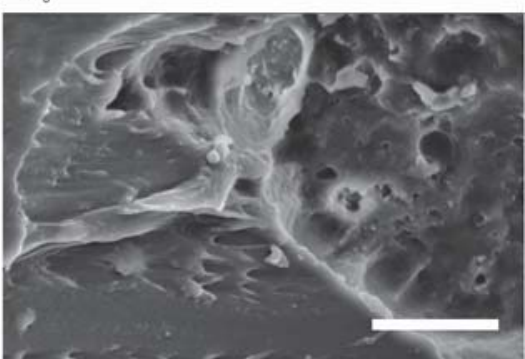

$b_{3}$ )

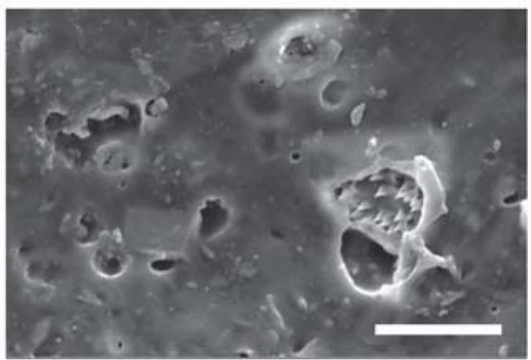

c)

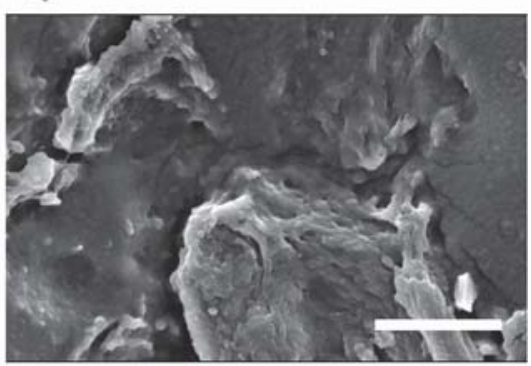

$d_{3}$ )

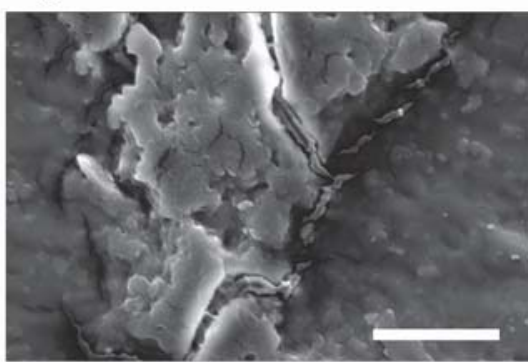

$e_{3}$ )

Figure 6. Surface morphology of PBFCL during enzymatic degradation at several intervals: $\left(\mathrm{a}_{1}-\mathrm{e}_{1}\right) 0$ days, $\left(\mathrm{a}_{2}-\mathrm{e}_{2}\right) 14$ days, and $\left(\mathrm{a}_{3}-\mathrm{e}_{3}\right) 28$ days. Scale bars: $10 \mu \mathrm{m}$.

\section{Acknowledgements}

The authors wish to thank Dr. Yajie Zhang for providing the feedstock 2,5-furandicarboxylic acid. This work was supported by the National Natural Science Foundation of China (51473175, 51603212).

\section{References}

[1] Gandini A., Coelho D., Gomes M., Reis B., Silvestre A.: Materials from renewable resources based on furan monomers and furan chemistry: Work in progress. Journal of Materials Chemistry, 19, 8656-8664 (2009). https://doi.org/10.1039/B909377J 
[2] Gomes M., Gandini A., Silvestre A. J. D., Reis B.: Synthesis and characterization of poly(2,5-furan dicarboxylate)s based on a variety of diols. Journal of Polymer Science Part A: Polymer Chemistry, 49, 3759-3768 (2011). https://doi.org/10.1002/pola.24812

[3] Sousa A. F., Matos M., Freire C. S. R., Silvestre A. J. D., Coelho J. F. J.: New copolyesters derived from terephthalic and 2,5-furandicarboxylic acids: a step forward in the development of biobased polyesters. Polymer, 54, 513-519 (2013).

https://doi.org/10.1016/j.polymer.2012.11.081

[4] Casanova O., Iborra S., Corma A.: Biomass into chemicals: Aerobic oxidation of 5-hydroxymethyl-2-furfural into 2,5-furandicarboxylic acid with gold nanoparticle catalysts. ChemSusChem, 2, 1138-1144 (2009).

https://doi.org/10.1002/cssc.200900137

[5] Tong X., Ma Y., Li Y.: Biomass into chemicals: Conversion of sugars to furan derivatives by catalytic processes. Applied Catalysis A: General, 385, 1-13 (2010). https://doi.org/10.1016/j.apcata.2010.06.049

[6] Bicker M., Hirth J., Vogel H.: Dehydration of fructose to 5-hydroxymethylfurfural in sub- and supercritical acetone. Green Chemistry, 5, 280-284 (2003). https://doi.org/10.1039/B211468B

[7] Sousa A. F., Vilela C., Fonseca A. C., Matos M., Freire C. S. R., Gruter G-J. M., Coelho J. F. J., Silvestre A. J. D.: Biobased polyesters and other polymers from 2,5furandicarboxylic acid: A tribute to furan excellency. Polymer Chemistry, 6, 5961-5983 (2015).

https://doi.org/10.1039/c5py00686d

[8] Papageorgiou G. Z., Tsanaktsis V., Bikiaris D. N.: Synthesis of poly(ethylene furandicarboxylate) polyester using monomers derived from renewable resources: Thermal behavior comparison with PET and PEN. Physical Chemistry Chemical Physics, 16, 7946-7958 (2014). https://doi.org/10.1039/c4cp00518j

[9] Burgess S. K., Kriegel R. M., Koros W. J.: Carbon dioxide sorption and transport in amorphous poly(ethylene furanoate). Macromolecules, 48, 2184-2193 (2015). https://doi.org/10.1021/acs.macromol.5b00333

[10] Zhu J., Cai J., Xie W., Chen P-H., Gazzano M., Scandola M., Gross R. A.: Poly(butylene 2,5-furan dicarboxylate), a biobased alternative to PBT: Synthesis, physical properties, and crystal structure. Macromolecules, 46, 796-804 (2013).

https://doi.org/10.1021/ma3023298

[11] Zhou W., Wang X., Yang B., Xu Y., Zhang W., Zhang Y., Ji J.: Synthesis, physical properties and enzymatic degradation of bio-based poly(butylene adipate-cobutylene furandicarboxylate) copolyesters. Polymer Degradation and Stability, 98, 2177-2183 (2013). https://doi.org/10.1016/j.polymdegradstab.2013.08.025
[12] Wu L., Mincheva R., Xu Y., Raquez J-M., Dubois P.: High molecular weight poly(butylene succinate-cobutylene furandicarboxylate) copolyesters: From catalyzed polycondensation reaction to thermomechanical properties. Biomacromolecules, 13, 2973-2781 (2012). https://doi.org/10.1021/bm301044f

[13] Papageorgiou G. Z., Papageorgiou D. G., Terzopoulou Z., Bikiaris D. N.: Production of bio-based 2,5-furan dicarboxylate polyesters: Recent progress and critical aspects in their synthesis and thermal properties. European Polymer Journal, 83, 202-229 (2016). https://doi.org/10.1016/j.eurpolymj.2016.08.004

[14] Drobny J. G.: Thermoplastic polyether ester elastomers. in 'Handbook of thermoplastic elastomers' (ed.: Drobny J. G.) William Andrew, Norwich, 271-286 (2014). https://doi.org/10.1016/B978-0-323-22136-8.00011-9

[15] El Mejjatti A., Harit T., Riahi A., Khiari R., Bouabdallah I., Malek F.: Chemical recycling of poly(ethylene terephthalate). Application to the synthesis of multiblock copolyesters. Express Polymer Letters, 8, 544-553 (2014).

https://doi.org/10.3144/expresspolymlett.2014.58

[16] Ryynänen T., Nykänen A., Seppälä J. V.: Poly(CL/ DLLA- $b$-CL) multiblock copolymers as biodegradable thermoplastic elastomers. Express Polymer Letters, 2, 184-193 (2008).

https://doi.org/10.3144/expresspolymlett.2008.23

[17] Stempfle F., Schemmer B., Oechsle A-L., Mecking S.: Thermoplastic polyester elastomers based on longchain crystallizable aliphatic hard segments. Polymer Chemistry, 6, 7133-7137 (2015).

https://doi.org/10.1039/c5py01209k

[18] Kwiatkowska M., Kowalczyk I., Kwiatkowski K., Szymczyk A., Roslaniec Z.: Fully biobased multiblock copolymers of furan-aromatic polyester and dimerized fatty acid: Synthesis and characterization. Polymer, 99, 503-512 (2016).

https://doi.org/10.1016/j.polymer.2016.07.060

[19] Zhou W., Zhang Y., Xu Y., Wang P., Gao L., Zhang W., Ji J.: Synthesis and characterization of bio-based poly (butylene furandicarboxylate)- $b$-poly(tetramethylene glycol) copolymers. Polymer Degradation and Stability, 109, 21-26 (2014).

https://doi.org/10.1016/j.polymdegradstab.2014.06.018

[20] Kuwabara K., Gan Z. H., Nakamura T., Abe H., Doi Y.: Crystalline/amorphous phase structure and molecular mobility of biodegradable poly(butylene adipate-cobutylene terephthalate) and related polyesters. Biomacromolecules, 3, 390-396 (2002).

https://doi.org/10.1021/bm0156476

[21] Gorna K., Gogolewski S.: Biodegradable polyurethanes for implants. II. In vitro degradation and calcification of materials from poly( $\varepsilon$-caprolactone)-poly(ethylene oxide) diols and various chain extenders. Journal of Biomedical Materials Research, 60, 592-606 (2002). https://doi.org/10.1002/jbm.10100 
[22] Cheng X., Luo X., Li Z., Ma D.: Proton NMR characterization of chain structure in butylene terephthalate$\varepsilon$-caprolactone copolyesters. Journal of Polymer Science Part A: Polymer Chemistry, 37, 3770-3777 (1999). https://doi.org/10.1002/(SICI)10990518(19991015)37:20<3770::AID-POLA5>3.0.CO;2-7

[23] Wang C-H., Tsai P-H., Kan L-S., Chen C-W.: Synthesis and characterization of copolymeric aliphatic-aromatic esters derived from terephthalic acid, 1,4-butanediol, and $\varepsilon$-caprolactone by physical, thermal, and mechanical properties and NMR measurements. Journal of Applied Polymer Science, 127, 4385-4394 (2013). https://doi.org/10.1002/app.38005

[24] Nanaki S. G., Papageorgiou G. Z., Bikiaris D. N.: Crystallization of novel poly( $\varepsilon$-caprolactone)-block-poly (propylene adipate) copolymers. Journal of Thermal Analysis and Calorimetry, 108, 633-645 (2012). https://doi.org/10.1007/s10973-011-2155-8

[25] Matos M., Sousa A. F., Fonseca A. C., Freire C. S. R., Coelho J. F. J., Silvestre A. J. D.: A new generation of furanic copolyesters with enhanced degradability: Poly (ethylene 2,5-furandicarboxylate)-co-poly(lactic acid) copolyesters. Macromolecular Chemistry and Physics, 215, 2175-2784 (2014).

https://doi.org/10.1002/macp.201400175
[26] Tsanaktsis V., Vouvoudi E., Papageorgiou G. Z., Papageorgiou D. G., Chrissafis K., Bikiaris D. N.: Thermal degradation kinetics and decomposition mechanism of polyesters based on 2,5-furandicarboxylic acid and low molecular weight aliphatic diols. Journal of Analytical and Applied Pyrolysis, 112, 369-378 (2015).

https://doi.org/10.1016/j.jaap.2014.12.016

[27] Cao A., Okamura T., Ishiguro C., Nakayama K., Inoue Y., Masuda T.: Studies on syntheses and physical characterization of biodegradable aliphatic poly(butylene succinate-co-e-caprolactone)s. Polymer, 43, 671-679 (2002).

https://doi.org/10.1016/S0032-3861(01)00658-9

[28] Lipik V. T., Kong J. F., Chattopadhyay S., Widjaja L. K., Liow S. S., Venkatraman S. S., Abadie M. J. M.: Thermoplastic biodegradable elastomers based on $\varepsilon$-caprolactone and L-lactide block co-polymers: A new synthetic approach. Acta Biomaterialia, 6, 4261-4270 (2010). https://doi.org/10.1016/j.actbio.2010.05.027

[29] Yang J., Webb A. R., Ameer G. A.: Novel citric acidbased biodegradable elastomers for tissue engineering. Advanced Materials, 16, 511-516 (2004). https://doi.org/10.1002/adma.200306264

[30] Gigli M., Negroni A., Soccio M., Zanaroli G., Lotti N., Fava F., Munari A.: Influence of chemical and architectural modifications on the enzymatic hydrolysis of poly(butylene succinate). Green Chemistry, 14, 28852893 (2012).

https://doi.org/10.1039/c2gc35876j 